\title{
Mandibular Fractures at Sylvanus Olympio Teaching Hospital: About 153 Cases
}

\author{
Haréfétéguéna Bissa*, Saliou Adam, Winga Foma, Palokina Agoda, \\ Essobozou Plaodèzina Pegbessou, Essolam Tagba, Bathokédéou Amana, Eyawèlhon Kpemissi
}

${ }^{1}$ Department of Stomatology, Otorhinolaryngology, Maxillofacial and Head and Neck Surgery, Health Sciences Faculty, University of Lomé, Lomé, Togo

${ }^{2}$ Department of Dentistry, Health Sciences Faculty, University of Lomé, Lomé, Togo

Email: *christophebissa@hotmail.fr

How to cite this paper: Bissa, H., Adama, S., Foma, W., Agoda, P., Pegbessou, E.P., Tagba, E., Amana, B. and Kpemissi, E. (2017) Mandibular Fractures at Sylvanus Olympio Teaching Hospital: About 153 Cases. Open Journal of Stomatology, 7, 501-510.

https://doi.org/10.4236/ojst.2017.712047

Received: October 5, 2017

Accepted: December 1, 2017

Published: December 4, 2017

Copyright $\odot 2017$ by authors and Scientific Research Publishing Inc. This work is licensed under the Creative Commons Attribution International License (CC BY 4.0).

http://creativecommons.org/licenses/by/4.0/

\begin{abstract}
Introduction: Mandibular fractures have epidemiological and therapeutic characteristics that vary from one region to another. The aim of our work was to report the particularities of this pathology in Lomé. Material and Methods: We analyzed retrospectively the records of 153 patients admitted for mandibular fractures in the ENT and Head and Neck and Maxillofacial Surgery Department of the Sylvanus Olympio Teaching Hospital in Lomé, between 2010 and 2015. Age, sex, etiology, topography and the therapeutic modalities were the parameters of study. Results: The prevalence of mandibular fractures was $15 \%$ with a sex ratio of 9.2. The average age was $33.5+/-$ 11.4 years with extremes of 7 years and 67 years. The etiology was marked by the predominance of road accidents (RA) in $63.3 \%$ followed by accidents at work in $14.4 \%$ and $80.4 \%$ motorcyclists involved. Unifocal fractures were found in $68.6 \%$ and the parasymphyseal region was the most affected (47\%) followed by the corpus (17.7\%). The osteosyntheses were performed in $71.9 \%$ and intermaxillary fixation in $13.7 \%$. The sequelae were noted in 12 patients (tooth loss, paresthesia in the lower dental nerve area). Discussion: Our results are superimposable with publications in developing countries. Mandibular fractures remain as the prerogative of young men of the 2nd and 3rd decades. However, treatment using modern methods (screw plate osteosynthesis) is still dependent on socioeconomic status.
\end{abstract}

\section{Keywords}

Mandible, Fracture, Epidemiology, Treatment, Togo

\section{Introduction}

The mandibular fractures were first evoked around $1650 \mathrm{BC}$ [1]. Only with the 
mobile bone of the face and its advanced position, the mandible is more often reached by the vulnerable object and presents topographic predominances differently reported in the literature [2]. The causes and implications of mandibular fractures vary with geographic region, socio-economic status, culture, religion and age [3]. These fractures are mainly caused by traffic accidents, sports accidents, firearms, physical attacks and pathological conditions (tumors, infections, metabolic diseases) [3]. The mandibular fractures have repercussions to varying degrees, according to their anatomoclinical form and their localization, on the manducatory function and the aesthetics of the face [2]; that is why we initiated this study with the objective of taking up the epidemiological and anatomoclinical aspects of mandibular fractures in our environment.

\section{Materials and Methods}

This was a retrospective study from 2010 to 2015 (6 years). It took place in the ENT and Head and Neck and Maxillofacial Surgery department of the Sylvanus Olympio Teaching Hospital (CHU SO) of Lomé. This department of 25 beds with an occupancy rate of about $80 \%$ accommodates in average twelve thousand consultants each year. The Sylvanus Olympio Teaching Hospital is the largest health training of Togo. This center of 983 beds welcomes average 50,774 consultants per year. Lomé is the capital of TOGO, country of West Africa. This department houses the only unit of Maxillofacial Surgery and Stomatology of the country taking care of the traumatisms of the face. We considered for this study the records of patients hospitalized for isolated or associated mandibular fracture and treated under general anesthesia. We excluded cases of mandibular fractures treated externally and pathological fractures. One hundred and fiftythree (153) files were thus listed.

For each patient, socio-epidemiological parameters were chosen: age, sex, occupation, history, circumstances and mechanism, and time of occurrence (year, month, and day). The clinical data studied were: number and topography of fracture line (s), association with other skeletal lesions. The topography of the fractures was established according to the topographic classification adopted by Touré et al. [4]. We also noted for each patient the type of treatment osteosynthesis and/or maxillary-mandibular fixation, and the post-therapeutic evolution.

\section{Results}

\subsection{Epidemiological Aspects}

During the study under review, 1021 maxillofacial pathologies were recorded including 405 maxillofacial traumas with 153 cases of mandibular fractures. The prevalence was then $15 \%$ compared to all the maxillofacial pathologies and $37.8 \%$ compared to the trauma of the face. The 153 patients were divided into 138 men $(90.2 \%)$ and 15 women (9.8\%) with a sex ratio of 9.2. The average age was $33.5+/-11.4$ years with extremes of 7 years and 67 years. The age groups 20 - 29 and 30 - 39 represented $34.6 \%$ and $31.4 \%$ respectively (Table 1 shows age, 
sex and professional distribution). The circumstances of the fracture occurred were road accidents in 106 cases (63.3\%), followed by work accidents in 22 cases (14.4\%), brawl (9.8\%), domestic accident (2.6\%), gun trauma (2.6\%) and sport accidents (1.3\%). These accidents involved $80.4 \%$ of motorcyclists and $6.8 \%$ of pedestrians. The direct impact mechanism with forward head tilt and anteroposterior impaction was reported in 123 patients (80.39\%) and indirect shock in 30 patients (19.61\%). The annual and monthly distributions are illustrated respectively by Figure 1 and Figure 2 .

\subsection{Anatomoclinic Aspects}

Diagnostic confirmation was obtained by a maxillofacial CT-Scan in 105 patients (68.63\%) followed by Orthopantomogram (OPT) in 43 patients $(28.43 \%)$ and in

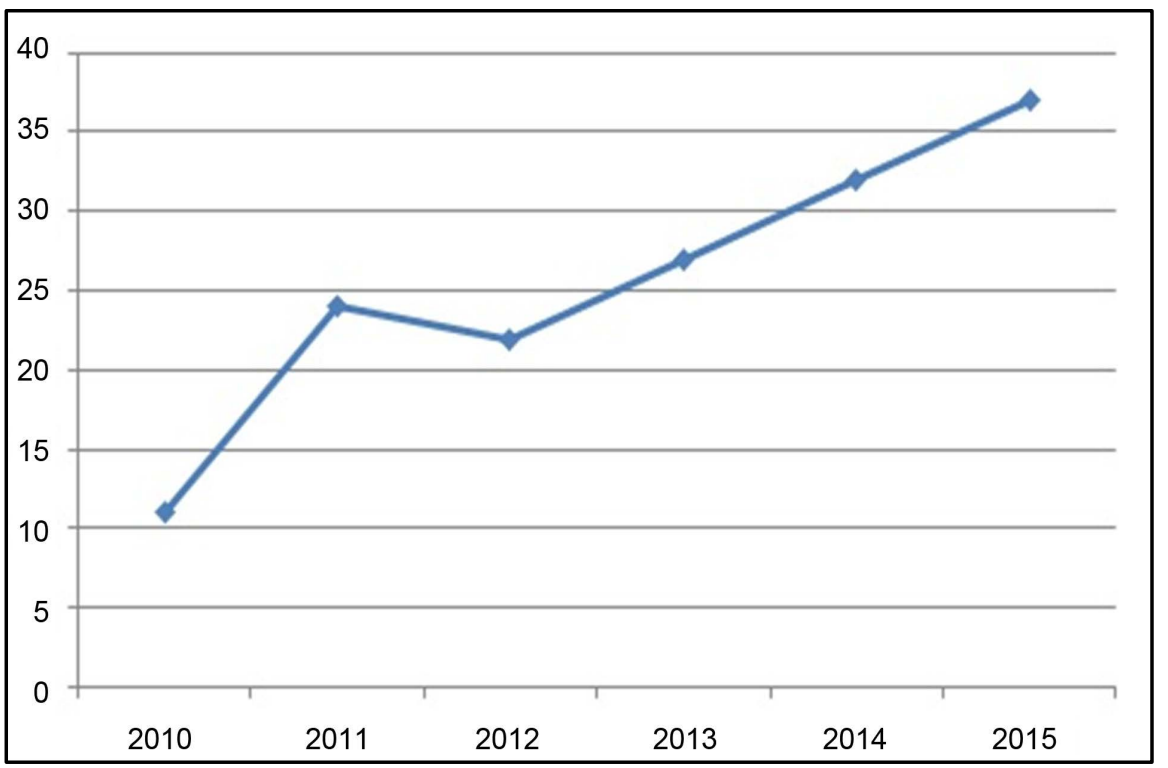

Figure 1. Distribution per year.

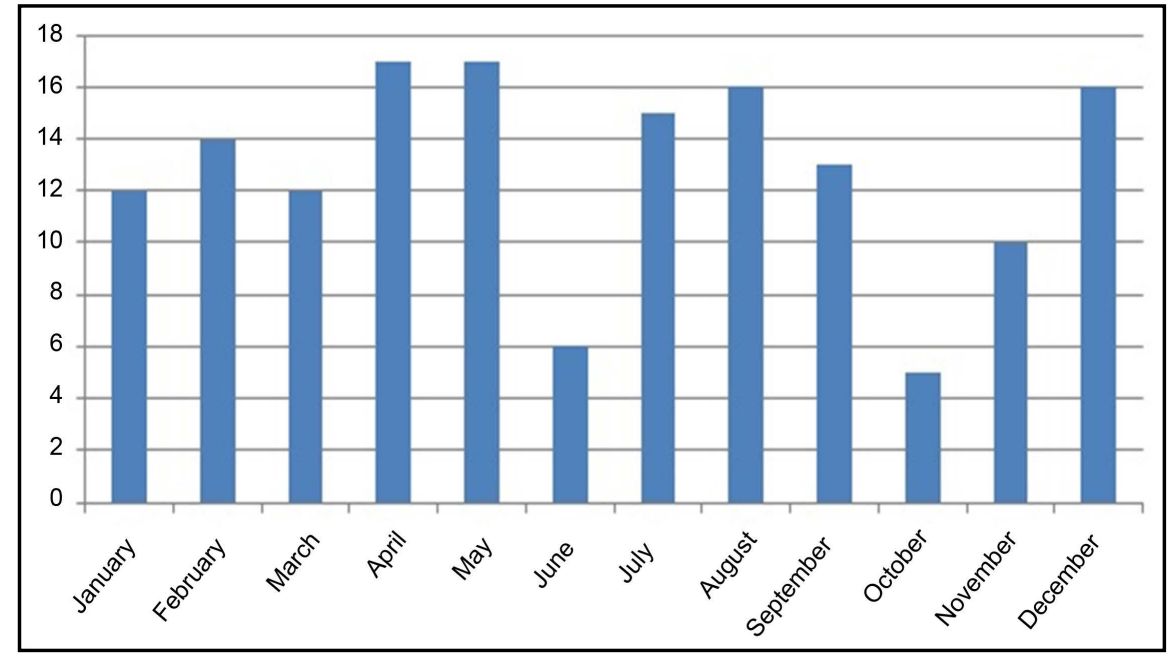

Figure 2. Distribution per month. 
Table 1. Age, sex and professional distribution.

\begin{tabular}{|c|c|c|}
\hline & Number (n) & Percentage (\%) \\
\hline \multicolumn{3}{|l|}{ Sex } \\
\hline Male & 137 & 89.5 \\
\hline Female & 16 & 10.5 \\
\hline Total & 153 & 100 \\
\hline \multicolumn{3}{|l|}{ Age } \\
\hline $0-9$ & 3 & 2 \\
\hline $10-19$ & 6 & 3.3 \\
\hline $20-29$ & 55 & 35.9 \\
\hline $30-39$ & 49 & 32 \\
\hline $40-49$ & 28 & 18.3 \\
\hline $50-59$ & 11 & 7.2 \\
\hline$\geq 60$ & 2 & 1.3 \\
\hline Total & 153 & 100 \\
\hline \multicolumn{3}{|l|}{ Socio-professional category } \\
\hline liberal profession & 63 & 41.2 \\
\hline Defence and security forces & 26 & 17 \\
\hline Civil servants & 24 & 15.7 \\
\hline Students/pupils & 18 & 11.7 \\
\hline Housewife & 5 & 3.3 \\
\hline without profession & 17 & 11.1 \\
\hline Total & 153 & 100 \\
\hline
\end{tabular}

the standard X-ray of the face in 5 patients (image of CT-Scan of patient is presented in the Figure 3). A total of 215 fractures were reported (average of 2.05 fractures per patient). Single fractures were found in 105 patients (68.6\%), two fractures in 41 patients (26.8\%) and those with at least 3 fractures in seven patients (4.6\%) (Table 2 shows mandibular fractures description). The symphyseal region (symphysis and parasymphysis) was the site of fracture in $47 \%$ of cases, followed by the corpus in $17.7 \%$. Condylar fractures came in 4 th place. In multifocal fractures, the symphysis + corpus region association was found in $25 \%$ of the cases followed by the corpus + angle in $23 \%$. Alveolar dental lesions were associated in 53 patients (34.6\%).

\subsection{Therapeutic and Evolutive Data}

Intermaxillary fixation was performed in 21 patients (13.7\%): 15 patients with single fracture, four patients with two-faced fracture and two patients with at least 3 fractures. The duration of the blocking was on average 37 days (between 30 and 64 days, standard deviation: 9 , median $=44$ days). 


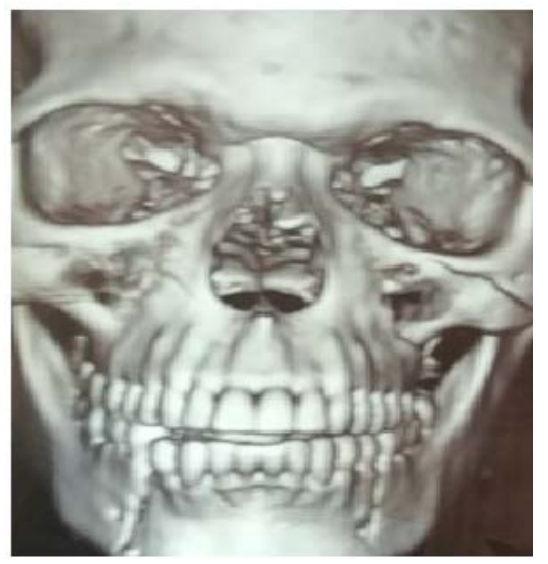

Figure 3. CT scan image of untreated mandibular and maxilla-zygomatic fracture.

Table 2. Mandibular fractures description.

\begin{tabular}{|c|c|c|}
\hline & Number (n) & Percentage (\%) \\
\hline \multicolumn{3}{|l|}{ Number of fracture lines $(n=153)$} \\
\hline Unifocal & 105 & 68.6 \\
\hline Bifocal & 41 & 26.8 \\
\hline At least three foci & 7 & 4.6 \\
\hline \multicolumn{3}{|l|}{ Anatomic site of fractures $(n=215)$} \\
\hline Symphysis and parasymphysis & 101 & 47 \\
\hline Body & 38 & 17.7 \\
\hline Angle & 29 & 13.5 \\
\hline Condyle & 24 & 11.2 \\
\hline Ramus & 16 & 7.4 \\
\hline Coronoïd & 7 & 3.2 \\
\hline \multicolumn{3}{|l|}{ Associations of fractures $(n=48)$} \\
\hline Symphyseal region + body & 12 & 25 \\
\hline Symphyseal region + condyle & 7 & 14.5 \\
\hline Angle + body & 11 & 23 \\
\hline Others & 18 & 37.5 \\
\hline
\end{tabular}

The osteosynthesis was performed in 110 patients (71.9\%): 81 patients for unifocal fracture, 27 patients with bifocal fracture and two patients with at least three fracture lines. Twenty-two patients (14.4\%) had osteosynthesis associated with intermaxillary fixation (Table 3 shows mandibular fractures treatment). Titanium screw plate osteosynthesis was performed in $91 \%$ of the cases.

Alveolar dental fractures had a cradle ligation (37\%) or a buccal ligation (67\%) (image of OPG of mandibular and maxilla-zygomatic fractures treated by Titanium screw plates is presented in Figure 4). The average duration of fixation or ligation was 18 days $+/-7$ days. 


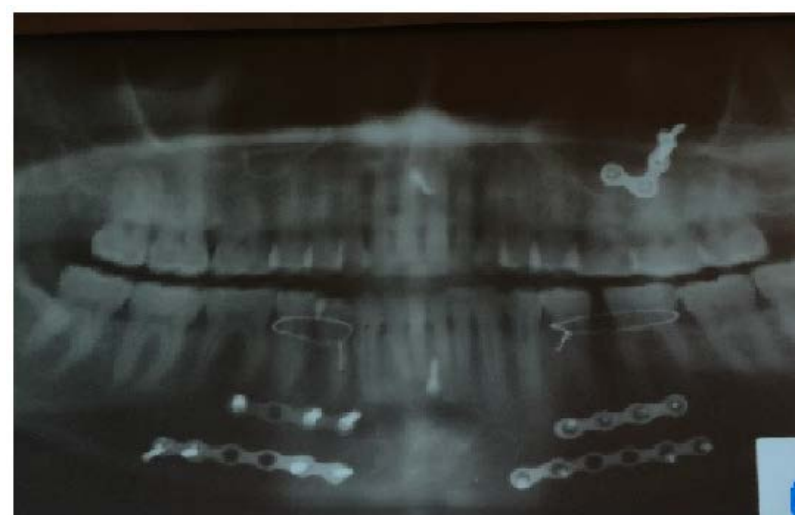

Figure 4. Orthopantomogramm of treated mandibular and maxilla-zygomatic fracture by titanium miniplates.

Table 3. Fractures treatment distribution.

\begin{tabular}{ccccccccc}
\hline & \multicolumn{2}{c}{$\begin{array}{c}\text { Orthopaedic } \\
\text { treatment }\end{array}$} & \multicolumn{2}{c}{$\begin{array}{c}\text { Surgical } \\
\text { treatment }\end{array}$} & \multicolumn{2}{c}{$\begin{array}{c}\text { Combined } \\
\text { treatment }\end{array}$} & \multicolumn{2}{c}{ Total } \\
\hline & $\mathrm{n}$ & $\%$ & $\mathrm{n}$ & $\%$ & $\mathrm{n}$ & $\%$ & $\mathrm{n}$ & $\%$ \\
\hline Unifocal & 15 & 9.8 & 81 & 53 & 9 & 5.8 & 105 & 68.6 \\
Bifocal & 4 & 2.6 & 27 & 17.6 & 10 & 6.6 & 41 & 26.8 \\
$\geq$ three fractures & 2 & 1.3 & 2 & 1.3 & 3 & 1.9 & 7 & 4.6 \\
Total & 21 & 13.7 & 110 & 71.9 & 22 & 14.4 & 153 & 100 \\
\hline
\end{tabular}

After an average follow-up of 9 months (extremes of 3 months to 7 years), the sequelae were noted in 12 patients (7.8\%). Six patients (3.9\%) had paresthesia in the mandibular nerve territory in 3 patients $(2 \%)$, one site infection with osteosynthesis in 2 patients $(1.3 \%)$ and one case $(0.6 \%)$ of dysfunction of the masticatory device.

\section{Discussion}

The prevalence of mandibular fractures in our series is $37.8 \%$. Because of its anteposition at the cephalic extremity, the mandible is more vulnerable to trauma. This prevalence should be relativized because our study did not take into account patients seen and treated externally, those treated in the dentistry departments of the capital and also in other cities of the country. Some patients were treated by dentist and others patients received traditional treatment. This frequency is variously reported in the literature: $22.6 \%$ in Grenoble (France), $25.2 \%$ in Madagascar, 50.3\% in Benin, 62\% in Tunisia [5] [6] [7] [8]. Mandibular fractures were the most frequent facial skeletal lesions in our study (37.8\%) and are the prerogative of the young adult male. Face trauma usually affects young male subjects and occurs most commonly during RA. In our study, we found predomination of the age groups $20-29$ and $30-39$ represented $34.6 \%$ and $31.4 \%$ respectively. These results are similar to those published in Africa and other developing countries (Nigeria, Egypt, and India) [9] [8] [9] [10] [11]. On the other 
hand, in developed countries, where the upsurge in facial trauma is moderated by the significant decrease in RA, it is due to the increase in interpersonal violence and the increasing practice of high level risk sport (79\% in Washington and 57\% in Paris) [1] [2] [12]. These RA involved 80.4\% of motorcyclists. Indeed, in the developed countries these were automobile accidents, while in our study, as in some countries in Africa and Asia, bicycles were involved. This result is not surprising in that road traffic growing disproportionately with road infrastructure is dominated by bicycles [7].

The most common radiological examination was the maxillofacial (68.63\%) CT-Scan followed by the OPT in $28.43 \%$. In most cases, CT-Scan is requested in surgical emergencies, cranial and facial injuries being commonly simultaneous, the latter being able to mask the first during the initial assessment; it allows an overall injuries assessment. The OPT was requested for the case of isolated trauma to the mandible. This approach is recommended for imaging useful in maxillofacial surgery [13].

In Lomé, we found predominance of fractures in the symphyseal region (47\%) followed by fractures of the body (17.7\%). Published works on the subject show extreme variability in topographic distribution. Indeed, for some authors, fractures are more frequent on the body (38.8\%), for others it is on the angle (42.3\%) and for others still on the condyles (36.4\%) [14]. However, in a quasi-consensual manner, the topography of mandibular fractures seems to be related to the etiology: angular fractures are frequent in case of brawls, falls predominate in condylar fractures, and RA cause fractures in the symphyseal region and condylar fractures due to the anteroposterior shock mechanism [13] [14]. We found a predominance of unifocal fractures with a major etiology of RA. Although the publications report that RA most often cause multifocal fractures, the difference in this work is due to the fact that these RA are due to non-high- speed bicycles [13] [15]. The RA in Lomé are dominated by bicycles accidents. In the case of multifocal fractures, no significant difference was found in our work $(\mathrm{p} \leq 0.05)$.

Intermaxillary fixation was performed in $13.7 \%$ of patients and predominates on unifocal fractures. This result is lower than the publications reported by developing and some developed countries [8] [9] [16]. Surgical treatment (osteosynthesis) was most performed (71.9\%). This rate is comparable to that found in the France series [12] and the Japanese series [17]. Indeed, according to some authors if the isolated intermaxillary fixation can indeed be conceived in certain cases (and in particular in the absence of maxillofacial surgeon trained in the techniques of osteosynthesis, in the case of comminutive fractures or seen late, for example) this type of treatment should no longer be proposed as a first-line treatment in reference centers [12]. In Lomé, the availability of implants and their accessibility to patients favored by a national health insurance, allowed these osteosynthesis. However, all authors agree that whatever the type of treatment proposed, the requirements to be taken into account are patient comfort, stability of assembly, resumption of activities, availability of implants [4] [14] 
[18]. The treatment made externally is always intermaxillary fixation. The sequelae noted in our series after 9 months of decline were mainly tooth losses. It is also the most widely reported type of complication in the literature [10] [18] [19]. Initial neurosensory disorders in the territory of mandibular nerve are frequent. The causes can be traumatic (contusion, more rarely section of the nerve) or iatrogenic during osteosynthesis. Subsequent hypoaesthesia is more rare. We found it in $4.2 \%$ of our patients.

\section{Conclusion}

This study, as a retrospective study some missing data are noticed because of the lack of archive room and computerization of medical files. These materials are important for the further studies.

\section{Acknowledgements}

Sincerely thank you to the staff of Oral and Maxillofacial Surgery and ENT and Cervico-Facial Surgery Units for record keeping and records that were used to conduct this study.

\section{Ethical Approval}

Authors obtained the approval of the ethics committee of the center for the conduct of this study.

\section{Conflict of Interest}

Authors declare that there is no any conflict of interest.

\section{References}

[1] Ogundare, B.O., Bonnick, A. and Bayley, N. (2003) Pattern of Mandibular Fractures in an Urban Major Trauma Center. Journal of Oral and Maxillofacial Surgery, 61, 713-718. https://doi.org/10.1053/joms.2003.50118

[2] Fridrich, K.L., Pena-Velasco, G. and Olson, R.A. (1992) Changing Trends with Mandibular Fractures: A Review of 1,067 Cases. Journal of Oral and Maxillofacial Surgery, 50, 586-589. https://doi.org/10.1016/0278-2391(92)90438-6

[3] Gadicherla, S., Kamath, A.T., Sasikumar, P., Gill, S.S., Pentapati, K.C. and Bhagania, M. (2015) Profile of Mandibular Fractures in a Tertiary Care Hospital: Retrospective Institutional Study. Universal Research Journal of Dentistry, 5, 185-188. https://doi.org/10.4103/2249-9725.162796

[4] Touré, G., Meningaud, J.P. and Bertrand, J.C. (2004) Fractures de la mandibule. In: Encyclopédie médico-chirurgicale. Stomatologie, Paris, 22-070-A-10.

[5] Razafindrabe, J.A.B., Rakotoarisoa, A.H.N., Rakoto, F.A., Randriamanantenasoa, V.H., Rakotozafy, L.F. and Rakotovao, J.D. (2007) Epidemiology of Mandible Fractures Treated at the University Hospital Center of Antananarivo-Madagascar. Revue tropicale de Chirurgie, 1, 33-35.

[6] Lebeau, J., Kanku, V., Duroure, F., Morand, B., Sadek, H. and Raphaël, B. (2006) Traumatismes faciaux au CHU de Grenoble: éTude épidémiologique de 961 dossiers sur une période de 365 jours. Revue de Stomatologie et de Chirurgie Maxil- 
lo-Faciale, 107, 23-29. https://doi.org/10.1016/S0035-1768(06)76977-7

[7] Bancolé Pognon, S.A., Biotchane, I. and Akpovi, G.D. (2013) Prise en charge des fractures mandibulaires à l'hôpital Saint Luc de Cotonou (Bénin). A propos de 83 cas. Médecine Buccale Chirurgie Buccale, 19, 85-89. https://doi.org/10.1051/mbcb/2013058

[8] Bouguila, J., Zairi, I., Khonsari, R.H., Lankriet, C., Mokhtar, M. and Adouani, A. (2009) Particularités épidémiologiques et thérapeutiques des fractures de mandibule au CHU Charles-Nicolle de Tunis. Revue de Stomatologie et de Chirurgie Maxillo-Faciale, 110, 81-85. https://doi.org/10.1016/j.stomax.2008.11.003

[9] Adebayo, E.T., Ajike, O.S. and Adekeye, E.O. (2003) Analysis of the Pattern of Maxillofacial Fractures in Kaduna, Nigeria. British Journal of Oral and Maxillofacial Surgery, 41, 396-400. https://doi.org/10.1016/S0266-4356(03)00165-7

[10] Sakr, K., Farag, I.A. and Zeitoun, I.M. (2006) Review of 509 Mandibular Fractures Treated at the University Hospital, Alexandria, Egypt. British Journal of Oral and Maxillofacial Surgery, 44, 107-111. https://doi.org/10.1016/j.bjoms.2005.03.014

[11] Subhashraj, K., Nandakumar, N. and Ravindran, C. (2007) Review of Maxillofacial Injuries in Chennai, India: A Study of 2748 Cases. British Journal of Oral and Maxillofacial Surgery, 45, 637-639. https://doi.org/10.1016/j.bjoms.2007.03.012

[12] Rocton, S., Chaine, A., Ernenwein, D., Bertolus, C., Rigolet, A., Bertrand, J.C., et al.. (2007) Fractures de la mandibule: Epidémiologie, prise en charge thérapeutique et complications d'une Br J Oral Maxillofac Surg série de 563 cas. Revue de Stomatologie et de Chirurgie Maxillo-Faciale, 108, 3-10.

https://doi.org/10.1016/j.stomax.2006.11.001

[13] Bourjat, P. (2006) L'imagerie utile en chirurgie maxillofaciale. Premiere partie: Avantages et inconvénients des modalités d'examen. Revue de Stomatologie et de Chirurgie Maxillo-Faciale, 107, 86-92. https://doi.org/10.1016/S0035-1768(06)76994-7

[14] Gadicherla, S., Kamath, A.T., Sasikumar, P., Gill, S.S., Pentapati, K.C. and Bhagania, M. (2015) Profile of Mandibular Fractures in a Tertiary Care Hospital: Retrospective Institutional Study. Universal Research Journal of Dentistry, 5, 185-188. https://doi.org/10.4103/2249-9725.162796

[15] Ramadhan, A., Gavelin, P., Hirsch, J.M. and Sand, L.P. (2014) A Retrospective Study of Patients with Mandibular Fractures Treated at a Swedish University Hospital 1999-2008. Annals of Maxillofacial Surgery, 4, 178-181. https://doi.org/10.4103/2231-0746.147119

[16] Tine, S.D., Tamba, B., Niang, P., Barry, C.G., Kébé, N.F., Guèye, N.F., Guèye, I. and Diallo, B. (2009) Fractures de la mandibule en pratique odontologique: A propos de 103 cas. Médecine Buccale Chirurgie Buccale, 15, 137-145. https://doi.org/10.1051/mbcb/2009012

[17] Feller, K.U., Schneider, M., Hlawitschka, M., Pfeifer, G., Lauer, G. and Eckelt, U. (2003) Analysis of Complications in Fractures of the Mandibular Angle-A Study with Finite Element Computation and Evaluation of Data of 277 Patients. Journal of Cranio-Maxillo-Facial Surgery, 31, 290-295.

https://doi.org/10.1016/S1010-5182(03)00015-5

[18] Brignol, L., Ricbourg, L., Meyer, C. and Ricbourg, B. (2006) Séquelles esthétiques et fonctionnelles à long terme des victimes d'un fracas facial associé à un traumatisme crânien. Revue de Stomatologie et de Chirurgie Maxillo-Faciale, 107, 233-243. https://doi.org/10.1016/S0035-1768(06)77045-0

[19] Cantaloube, D., Daupleix, C., Chikhani, L. and Caucanas, D. (2006) Séquelles des 
H. Bissa et al.

traumatismes dentaires: Aspects me'dico-le'gaux. Revue de Stomatologie et de Chirurgie Maxillo-Faciale, 107, 294-302.

https://doi.org/10.1016/S0035-1768(06)77052-8 